\title{
Internet and Juvenile Prevention: A New Format of Prophylactic Activities with Children
}

\author{
Mykola Veselov*[0000-0002-3963-2764], Serhiy Vitvitsky [0000-0002-4884-1883]
}

Donetsk Law Institute of the Ministry of Internal Affairs of Ukraine, Kryvyi Rih, Ukraine

*veselovndl@ukr.net

\begin{abstract}
The research study focuses on specific issues of delinquency prevention and other deviant juvenile manifestations. Taking into account the impact of virtual environment on the formation of communication links within society and the consciousness of social groups or individuals, it has turned out on the initiation of this publication, the main purpose of which is to determine the capability and the effectiveness of the Internet and mobile applications results in the field of juvenile delinquency prevention. It is emphasized that for the police the Internet in the system of juvenile delinquency prevention becomes either an object of attention as possible determinant of juvenile deviation or means of preventive influence exerting on the consciousness and behavior of children. Keeping this in mind, the specifics of general and individual prevention activities with "the risk group" of children has been determined in a new format, i.e. using the Internet and mobile applications.
\end{abstract}

Keywords: juvenile prevention, prophylaxis, child, Internet, mobile application, persuasion.

\section{INTRODUCTION}

The state of juvenile delinquency (misdemeanor committed by underage children) has been and still remains urgent problem for Ukraine. The average number of the minors who have committed criminal offenses during the last five years is almost 3,500 cases. And although according to the statistics of the Office of the Prosecutor General this number decreases every year (analysis of these indicators (for 11 months) during 20162020 shows decrease of $29.9 \%$ [1]), this situation cannot leave indifferent the government nor society in the whole. Also, we should mention on the great number of administrative offenses committed by this category of persons, as well as emphasize on the significant percentage of juvenile offenses in Ukraine that remain latent. The solution of this problem goes far beyond the scopes of legal liability only. These legal relations cover a number of aspects, the main of which are the application of moderate infant-friendly response measures from the part of state bodies and local communities, special procedures for jurisdictional proceedings (criminal and administrative-delict), ensuring the rights of such children, withdrawing subjective and objective reasons contributing to the demoralization of minors, further relapses on their part, and finally taking up prevention measures. Today, juvenile justice is being a guiding theoretical and political principle of the best form of ensuring the rights of children who are in difficult living circumstances, in particular at risk [2] or in conflict with the law [3, p. 127128]. Currently dominating in Ukraine criminally legitimate (mostly punitive) approach to solving the problems of delinquency among children quite formally takes into account their interests being characterized by its retrospective nature $[4$, p. 50]. Every year the number of children convicted by the Courts is actually equal to $1 / 2$ of registered cases on criminal offenses committed by this age group category. However, taking into account the peculiarities of juvenile age, the prosecution should not always be the only possible response by the state for the offenders mentioned [5, p. 152]. Ensuring the widest range of interests of any infant occurred within a conflict to the law and trying to return the child back into society as soon as possible require quite a wholesome set of legal, social, educational, medical and organizational measures available in the arsenal of juvenile justice. In addition, efforts on the part of the state and the community should be aimed primarily at preventing offenses, which determines the priority of preventive activity.

Thus, the purpose of this study is to determine the ability and effectiveness of the Internet and mobile applications capacity in the field of juvenile prevention. 


\section{RESEARCH METHODOLOGY}

In order to achieve the set-up goal, generally scientific and specially applied methods have been used during the investigation, being the means of scientific research (structural-functional and systemic, formallylogical, hermeneutic, etc.). The overall reports of the Office of the Prosecutor General on persons who committed criminal offenses within 2016-2020 allowed us to determine dynamics and trends of criminal offenses among the minors in Ukraine over the past five years. In addition, the study is based on the generalization of the results of the implementation of a local pilot project on individual prevention with children who are registered in by the police (City of Kryvyi Rih) using mobile applications like Viber and Google Meet. Within the framework of this project the conducted surveys and questionnaires of children allowed us to find out the advantages and disadvantages of the new format of preventive activities.

\section{RESEARCH RESULTS}

The UN Committee on the Rights of the Child believes that the policy of administering justice to minors without a set of measures aimed at preventing juvenile delinquency suffers from serious shortcomings [6, p. 8]. It is not surprising, therefore, that English (Crime and Disorder Act 1998, Art. 37) [7], Canadian (Youth Criminal Justice Act. 2002, preamble) [8] state that the main purpose of juvenile justice is to prevent juvenile and youth delinquency. Therefore, any system of juvenile justice, that is activities like prevention (prophylaxis) of crimes committed by children, should be considered as one of its main principles and priorities.

The determinants of juvenile delinquency can be divided into the following groups: social and economic, organizational and legal, cultural and psychological [9, p. 122]. Having rested on these classification, preventive measures can be divided into general (socio-economic, legal) and individual (special) ones, or their prophylactic measures like earlier (initial) intervention, rehabilitation [10].

In most countries of the world the main subject of counteraction to juvenile delinquency are police units [5, p. 156]. For example, in the United States there are 5 stages of working with juvenile offenders, including police proceedings, pre-trial inspection, bringing the case to the Court, and so on. Discrete powers of the police at each stage allow to individualize the impact on the kid in specific situations. The application of preventive measures and measures of deterrence to juvenile offenders out of Court takes place in almost $90 \%$ of cases $[5$, p. 152]. It goes without saying that these activities are organized and carried out by the police in close cooperation with other government agencies and the community, using a variety of forms and methods.
According to the legislation of Ukraine, prevention of offenses among children is an activity aimed at identifying and eliminating the causes and conditions that lead to the commission of administrative and criminal offenses by children, as well as a positive impact on the behavior of individual minor in Ukraine, in a particular region and within the family, at the enterprise, institution or organization, regardless of ownership or place of residence [11, Art. 3].

Today, the Internet through computers, mobile devices, various software is increasingly penetrating public relations and personal lives, creating a new form of virtual communication. We may assume that such a communication leads to the formation of a specific media culture among adolescents. Fascination with the Internet has both advantages and disadvantages. Through browsers and social networks, a child can find needed information very quickly, provide online communication, education, stay in touch with their parents, and many more. For example, in conditions of global pandemic, educational institutions are actively using online education. And although these alternatives may not fully compensate the benefits of full-time training, they provide flexibility and continuity of communication with the online audience, regardless of the location of participants [12, p. 18]. According to the international research project ESPAD, in 2019 only $6.7 \%$ of surveyed adolescents in Ukraine did not use social networks. Almost $45 \%$ of adolescents spend up to 3 hours a day on social networks, and about $50 \%-4$ or more hours [13]. At the same time, free placement and access to personal information, uncontrolled content of sites and social networks, the possibility of negative information and psychological impact on the unstable consciousness of the child, along with the benefits of the Internet, creates information security problems that require not only technological but also social legal solutions [14, p. 40]. Against the background of expanding possibilities of virtual communication through social networks and software applications like Facebook, YouTube, Instagram, Twitter, WhatsApp, Viber, Telegram it is often necessary to observe actual social isolation of children and adolescents [15, p. 59-60], which leads to disorders of cognitive and communicative processes in real life. Children are often lack of useful information to assess the risks of their own behavior properly, or the possible factual and legal consequences of their actions.

The use of computers, smartphones and other electronic gadgets in order to attempt changes in human behavior is no longer uncommon today [16]. Nowadays it is already believed that the Internet can influence upon various aspects of a child's life and development, including politics, culture, religion, education, health, environment, and so on. Using technological, design and psychological methods of influencing the consciousness and subconsciousness of Internet users, the belief is 
always aimed at changing perception, attitude, behavior of both individuals and indefinite groups of people, sometimes forcing them to certain actions or inactions $[17$, p. 2]. Such intentions can be socially useful, neutral or, conversely, harmful. Children are most prone to persuasion. Therefore, the Internet in the system of juvenile prevention simultaneously becomes for the police both an object of attention as a possible determinant of juvenile deviation, and means of exerting preventive influence on the consciousness and behavior of children.

The police must monitor Internet content to identify threats to children's information security. However, the specifics of cyberspace stipulate the fact that to overcome all the threats and negative effects of the Internet for children in this area is not possible physically. Bearing this in mind, the police should focus their efforts on neutralizing mentioned threats using the Internet to prevent illegal acts by the minors.

Effective persuasive system should transfer the potential user to its scope through the following stages of persuasion: (1) the stage of attracting attention; (2) the stage of maintaining interest; (3) stage of action (when the user follows the target guidelines). The abovementioned stages, however, depend on the effective coverage of the system $[17, \mathrm{p} .3]$. It is necessary to monitor perpetually how this or that preventive content and the form of its proof are able to contribute to the process of forming children's acknowledgement about the interaction of "subject-object". This will provide an opportunity to develop a system of using this potential and better adaptation it to the needs of children [18, p. 78 ] and preventive tasks of the police in today's conditions either.

Preventive material designed to be posted on the Internet can provide children with necessary tools to assess external potential risks or predict consequences of their own actions. In addition to training guidelines and recommendations from the police on the dangers to children, their parents and other social subjects of control, this should be information on the most disturbing practices that are spreading, including through the Internet (such as sexting, bullying, fraud, ludomania, tote, involvement of adolescents into destructive communities, the spread of juvenile drug addiction, alcoholism, excessive aggression, etc.). There is the necessity to raise children's awareness of the algorithms for their actions if they are already in conflict with the law, the types and conditions of alternative measures of juvenile justice, ways to involve minors into illegal activities, etc. For example, the UK Government website has a Youth and the Law overview page, which contains information on "What happens if a child under the age of 10 breaks the law?", "What happens if your child gets into trouble with the police", etc. [19]. In order to draw the attention of Internet users to the most pressing issues on their websites, the Swedish Police, in addition to their own projects, also posts information from other social services and public organizations, such as the link "About young people and alcohol on the Teenårsparlören website" [20].

To achieve the effect of preventive effects on children through the Internet and mobile resources, it is necessary to adhere to the following principles: (1) there cannot be too much preventive information; (2) diversity of thematic content; (3) the extreme specificity of the content and experimental nature of the method of information presentation; (4) children should not look for the necessary and useful information for themselves, so this information "should find itself " necessary addressees, and the kids just have to separate it.

Active use of the Internet and mobile resources should be widespread among individual prevention measures with children who are on preventive registration in police departments. Mobile application technology can increase motivation of such people to socialize/re-socialize, since the adolescents of new generation are naturally inclined to the idea of using mobile phone (smartphone/iPhone) as often as possible. The traditional mode of contemporary education is increasingly being replaced by mobile teaching because of its role in shaping students' motivation [21; 22, p. 92], which cannot be left without proper attention in the context of prevention. Starting from September 2020, the project of individual preventive activity with the use of mobile applications was tested with children registered in Kryvyi Rih City (Dnipropetrovsk region). For children who own Viber software application in their modern mobile communication devices (this is $72 \%$ of the total population registered in the city) a chat was created, in which these persons became participants. Except juvenile preventive police officers, the administrators of this chat were specialists from a local center for free secondary legal aid, juvenile service, and juvenile psychologists. The capabilities of the software application allow quick bringing of necessary information to the group members from administrators (including the form of files), sharing links to useful sites, creating surveys to check recommended preventive material for review, questionnaires. In addition, chat allows to maintain constant feedback under quarantine restrictions with these people. Also, using a software application like Google Meet, periodic preventive interviews and lectures can be conducted with the participants of the mini-groups by video conference with both police and involved specialists (psychologists, teachers, lawyers, probation specialists, etc.).

It should be noted that $38 \%$ of children showed activity in participation as members of this project, moderate activity showed $29 \%$, minimum activity $-21 \%$, no activity at all $-12 \%$ (Figures 1 ). The first two months aroused the greatest interest in this form of interaction. 
Among the advantages of the project respondents identified: efficiency in proving information and ease of perception; "live" feedback with project administrators as the opportunity to ask questions and get answers; expansion of communicative connections among peers without excessive personal personalization; group opportunity to discuss some typical problems of adolescence or social confrontation; anonymity in questionnaires; some participants even noted a sense of moral support. Among the disadvantages there was the dependence on the quality of the mobile Internet; the general nature of preventive material without taking into account specifics of the social microenvironment of individuals; the schedule of "mandatory" video conference meetings through Google Meet is not always convenient for participants, and so on. In general, according to the results of anonymous survey, this form of preventive activity was positively perceived by $62 \%$ of project participants, satisfactory $-24 \%$, unsatisfactory $-2 \%$, no participation in the survey $-12 \%$ [23].

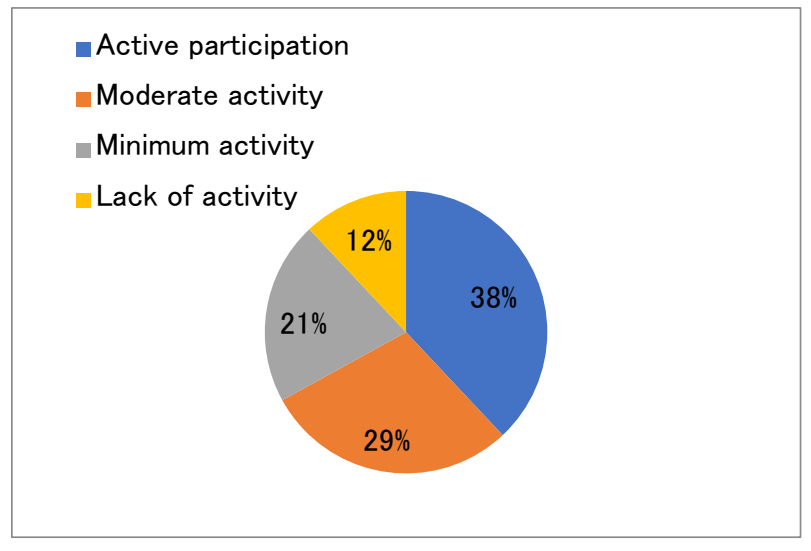

Figure 1 Preventive chat participants activity

\section{RESULTS DISCUSSION}

Prohibitory and restrictive measures for children and adolescents on the Internet can arouse even greater interest in harmful Internet resources, making just additional advertisement for them. On the contrary, the police preventive measures can have positive effect on the consciousness and behavior of the minors. In this context, a belief system aimed at preventing deviant behavior among children should include the following: (1) understanding the etiology of risks and threats to children that occur within the social environment, including uncontrolled use of the Internet; (2) establishing causal links between the determinants of wrongful conduct and the forms of possible manifestations of juvenile deviation in order to take targeted countermeasures; (3) taking into account the specifics of juvenile psychology, in particular the perception of useful information and its corrective ability; (4) developing effective methods of neutralizing negative impact of antisocial environment (including destructive virtual environment) onto the child through risk awareness, legal education and positive impact on children's consciousness through mobile and online resources; (5) constant monitoring of the content of Internet resources and mobile applications in order to determine their rating among children and youth, as well as to identify and systematize threats to children; (6) proper response onto the threats to neutralize them.

The use of new mobile interactive forms of individual prevention with children of "risk groups" (children who are registered by the police) usually has its advantages and disadvantages. They are not able to solve general social problems or to improve financial situation of the child in some cases (but some socio-economic and general legal measures should be applied for prevention of causes of delinquency, child neglect, etc.). However, the establishment of feedback and atmosphere of trust between administrators and participants within the "virtual communication" can further signal on the presence of particular social and material problems inside the micro-environment of the child and respond on them more quickly. The coverage of a child with a preventive effect in this way depends on a certain material support like the ability to have a modern smartphone/iPhone, mobile Internet (ideally). In such a remote mode, it is difficult to force the child to be an active participant of the prevention process, so the only way to involve the kid into interaction is to create an atmosphere of interest that is to require new design and software solutions, psychological techniques and methods (preferably IT professionals and programmers, psychologists, teachers are to be involved, etc.).

\section{CONCLUSIONS}

The level of modern IT-technologies development, the emergence of new ways of mobile search and exchange of information or virtual communication certainly affects the social processes and psychology of some individuals. Thus, the effect of neutralizing the harmful effects of negative social factors and the formation of the acceptability of the rules of law and morality of social behavior for children of "risk groups" can be achieved through preventive content, which in its turn, minding the specifics of children's environment, can be posted onto the Internet, mobile phone applications in various designs and software formats.

In order to achieve positive effect, the specificity of the general preventive impact through the Internet lies in the maximum saturation of this space with useful information for an unlimited number of users (children, parents, teachers). In its turn, measures of individual prevention using the Internet and modern mobile applications with children of "risk groups" should preassume working in "small groups", taking into account 
the specifics of social microenvironment of these categories of persons.

The emergence of new prevention formats using information technology requires their constant testing and analyzing as for its effectiveness, which leads to the expansion of scientific research and further investigations in this area.

\section{REFERENCES}

[1] About persons who have committed criminal offenses: Statistical information (Summary data for Novem. 2016-2020). Website of Prosecutor General's Office of Ukraine, available at: https://www.gp.gov.ua/ua/stat_n_st?dir_id=11414 $1 \&$ libid=100820\&c=edit\&_c=fo.

[2] Korystin, O.Ye. and Svyrydyuk, N.P. (2020), "Methodological principles of risk assessment in law enforcement activity", Nauka i pravooxorona, vol. 3, pp. 191-197. DOI: https: //doi.org/10.36486/np.2020.3(49).19

[3] Veselov, M.Yu. (2020), "Preventive measures in the legal doctrine of juvenile justice", Economic Theory and Law: col. of sci. papers, No. 1(40), pp. 127-141. DOI: 10.31359/24115584-2020-40-1-127.

[4] Veselov, M. (2020), "Administrative and legal ensure of "the best interests of the child" in the field of junior justice", Public Administration and Law Review, issue 3, pp. 49-56. DOI: https://doi.org/10.36690/2674-5216-2020-3-49.

[5] Park, J.-R. and Noe, S.-O. (2020), "Research on international examples on prevention of juvenile delinquency", Journal of The Korea Society of Computer and Information, vol. 25, No. 8, pp. 151157.

DOI: https://doi.org/10.9708/jksci.2020.25.08.151.

[6] UN Committee on the Rights of the Child (CRC), General comment No. 10 (2007): Children's Rights in Juvenile Justice, 25 April 2007, CRC/C/GC/10, available at: https://www.refworld.org/docid/4670fca12.html.

[7] Crime and Disorder Act 1998 (with all changes known to be in force on or before 26 Jan. 2020). UK Public General Acts, available at: http://www.legislation.gov.uk/ukpga/1998/37/cont ents.

[8] Youth Criminal Justice Act. S.C. 2002. Assented to Febr. 19, 2002. In the edition of on Decem. 18, 2019, available at: https://loislaws.justice.gc.ca/PDF/Y-1.5.pdf.
[9] Usmanova, M.A. and Akhmedova, M.T. "Some Comments On The Causes And Conditions Of The Offenses", The American Journal of Political Science Law and Criminology, 2020, vol. 02, issue 11, pp. 120-124. DOI: https://doi.org/10.37547/tajpslc/Volume02Issue 11 -19 .

[10] Butts, J.A. and Mears, D.P. (2001). "Reviving Juvenile Justice in a Get-Tough Era", Youth and Society, vol. 33 (2), pp. 169-198.

[11] On bodies and services for children and special institutions for children: Law of Ukraine of Jan. 24, 1995 No. 20/95-VR. In the edition of Febr. 9, 2017, available at: https://zakon.rada.gov.ua/laws/show/20/95$\% \mathrm{D} 0 \% \mathrm{~B} 2 \% \mathrm{D} 1 \% 80 \#$ Text.

[12] Mubasher Hassan, M. Mirza, T. and Waseem, M. Hussain, (2020), "A Critical Review by Teachers on the Online Teaching-Learning during the COVID-19". I.J. Education and Management Engineering, vol. 10, No. 5, pp. 17-27. DOI: $10.5815 /$ ijeme.2020.05.03.

[13] Child safety on the Internet / Website of the Ministry of Science and Education of Ukraine. (n. d.), available at: https://mon.gov.ua/ua/osvita/pozashkilnaosvita/vihovna-robota-ta-zahist-pravditini/bezpeka-ditej-v-interneti.

[14] Alguliyev, R. and Ojagverdieva, S. (2019), "Conceptual Model of National Intellectucal System for Children Safety in Internet Environment", I.J. Computer Network and Information Security, vol. 3, pp. 40-47. DOI: $10.5815 /$ ijcnis.2019.03.06.

[15] Sobko, G. (2020), "Criminal and criminological factors affecting involvement of minors in illegal activities and inducement to use narcotics, psychotropic substances or their analogues", Public Administration and Law Review, vol. 3, pp. 57-66. DOI: https://doi.org/10.36690/2674-5216-2020-357.

[16] Kimura, H. and Nakajima, T. (2011), "Designing Persuasive Applications to Motivate Sustainable Behavior in Collectivist Cultures", PsychNology Journal, vol. 9 (1), pp. 7-28.

[17] Ebenezer, O. (2020), "Influencing Children: Limitations of the Computer-Human-Interactive Persuasive Systems in Developing Societies", I.J. Modern Education and Computer Science, vol. 5, pp. 1-15. DOI: 10.5815/ijmecs.2020.05.01. 
[18] Brunnet, N. and Portugal, C. (2016), "Digital Games and Interactive Activities: Design of Experiences to Enhance Children TeachingLearning Process", I.J. Modern Education and Computer Science, vol. 12, pp.1-9, DOI: 10.5815/ijmecs.2016.12.01.

[19] Browse: Young people and the law / GOV.UK. (n. d.), available at: https://www.gov.uk/browse/justice/young-people.

[20] Unga som begår brott - polisens arbete / Polisen. (n. d.), available at: https://polisen.se/ompolisen/polisens-arbete/ungdomsbrott/unga-sombegar-brott/.

[21] Baby, K.T. "Generating Internal Motivation through Mobile Application Technology", in N. Feza (Ed.), Metacognition in Learning, IntechOpen.

DOI: https://doi.org/10.5772/intechopen.88346.

[22] Rosmery Tambunan, L. Riani Siregar, N.A. and Susanti Susanti (2020), "Sosialisasi E-book Berbasis Smartphone pada Materi Polinomial di Kelas XI SMA Negeri 4 Tanjungpinang”, Jurnal Anugerah, vol. 2(2), pp.91-98. DOI: https://doi.org/10.31629/anugerah.v2i2.2521.

[23] Summary of the results of the analysis of the local project of individual prevention with children who are on the preventive register in the police using mobile applications Viber and Google Meet (in\%, 32 people). 